\title{
High-current Interruption in Vacuum Circuit Breakers
}

\author{
M. Binnendijk, W. F. H. Merck \\ Eindhoven University of Technology, Eindhoven, \\ R. P. P. Smeets \\ KEMA High Power Laboratory, Arnhem, The Netherlands \\ K. Watanabe and E. Kaneko \\ Toshiba Co., Tokyo, Japan
}

\begin{abstract}
The aim of this project was to find a correlation between contact gap length and switching behavior of a vacuum circuit breaker. A large number of interruption experiments was executed in a vacuum chamber with butt type contacts made of $\mathrm{Cu}, \mathrm{CuCr} 50 / 50$ and $\mathrm{AgWC}$. The currents to be interrupted varied from 2.5 to $32 \mathrm{kA}$. The rate of change of current and recovery voltage were kept at a fixed value at current zero. Many re-ignitions of the dielectric type, scattered over a wide range of re-ignition voltages, were observed and only a few of the thermal type. The total amount of energy dissipated in the vacuum chamber appears to be determinative for the type of re-ignition. On $\mathrm{Cu}$ severe anode spot melting was found, whereas $\mathrm{CuCr}$ and $\mathrm{AgWC}$ suffered little anode melting. The wide range of re-ignition voltage values found shows that a straight correlation with the contact gap length can not be defined. At 5 to $10 \mu$ s after current zero a 'second' post arc current did appear.
\end{abstract}

\section{INTRODUCTION}

$\mathrm{F}$ OR design and manufacturing it is important to know the current interruption performance of the VCB (vacuum circuit breaker) under different conditions, e.g. arc current, arcing time, gap length. After current zero the TRV (transient recovery voltage) appears over the opened contacts and can cause a re-ignition. Whether this happens or not depends on many parameters like: $d i / d t$ just before current zero, $d u / d t$ just after current zero, contact distance $d$ at current zero, peak value of the arc current, arcing time, contact material, and the shape of the contacts.

Especially the interruption performance of short circuit currents, in the range of $10 \mathrm{kA}$ is of interest. In this case current constriction and anode spot formation can occur easily [1-4]. When anode spot melting has occured the re-ignition will be of the thermal type due to the abundance of particles in the contact gap $[1,2]$. At low currents the recovery of dielectric strength depends, apart from the used contact material, on the rate of rise of current and voltage and on the gap length at current zero [5]. The experiments were performed with the following contact materials: $\mathrm{Cu}, \mathrm{CuCr} 50 / 50$ and AgWC (Toshiba Co.). The contacts used were of the butt type, so no axial magnetic field was induced. During the experiments the rates of rise of current and voltage were kept constant, thus for a specific experiment only the gap length, the peak value of the arc current and the arcing time varied.

\section{EXPERIMENTS}

\subsection{TEST GIRCUIT}

The experiments were executed with the well known Weil-Dobke synthetic circuit, shown in Figure 1. It consists of a main current circuit, containing a capacitor bank C $(890 \mu \mathrm{F})$, transformer T $\left(L_{t r}=\right.$ $21.5 \mathrm{mH}, R_{t r}=1.49 \Omega$ ) with $f_{\text {main }}=36.4 \mathrm{~Hz}$; a current injection circuit, containing: a capacitor $\mathrm{Cr}(27.8 \mu \mathrm{F})$, coil $\mathrm{L}(1.27 \mathrm{mH})$, and air gap switch SG, with $f_{i n j}=847 \mathrm{~Hz}, \widehat{i}_{i n j}=2.2 \mathrm{kA}$ and $\left(d i_{i n j} / d t\right)_{c z}=11.7 \mathrm{~A} / \mu \mathrm{s} ;$ a TRV circuit containing capacitor $C_{\mathrm{TRV}}$ $(20 \mathrm{nF})$ and coil $L_{d}(32 \mu \mathrm{H})$, with $f_{\mathrm{TRV}}=32 \mathrm{kHz}, \widehat{u}_{\mathrm{TRV}}=25 \mathrm{kV}$ and $d u_{\mathrm{TRV}} / d t=1.9 \mathrm{kV} / \mu \mathrm{s}$.

The test object is VCB-I, a demountable vacuum chamber equipped with butt type contacts of the different materials, all with a diameter of $25 \mathrm{~mm}$. VCB-II is a back up switch to prevent the TRV from entering the low voltage components of the main circuit. During the first half cycle of the main current, VCB-I and VCB-II are opened simultaneously, where VCB-II interrupts at main current zero, whereas VCB-T is still conducting the injection current which was triggered $0.3 \mathrm{~ms}$ before current zero. After current zero of the injection circuit the TRV only acts on VCB-I.

Figure 2 shows the full performance of a test run: (a) main and in jection current; (b) arc voltage; (c) arc light intensity and (d) gap length. The initial contact opening speed is $1.8 \mathrm{~m} / \mathrm{s}$ and the average speed until 


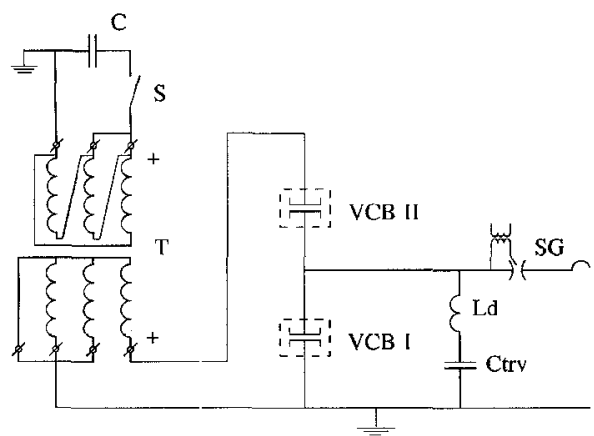

Figure 1. Main components of the Weil-Dobke synthetic circuit.
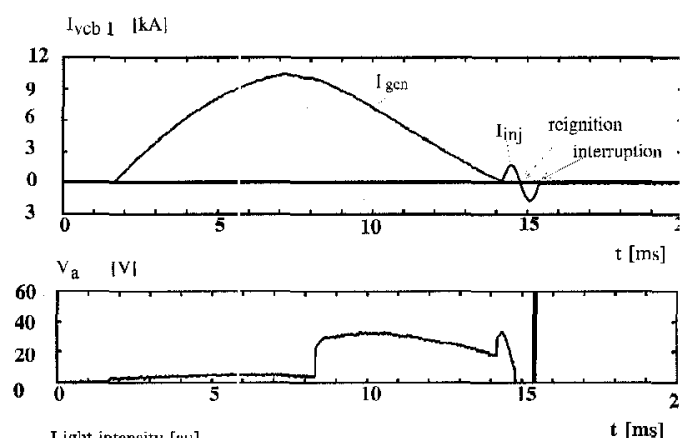

Lighit intensity [au]

t [ms]

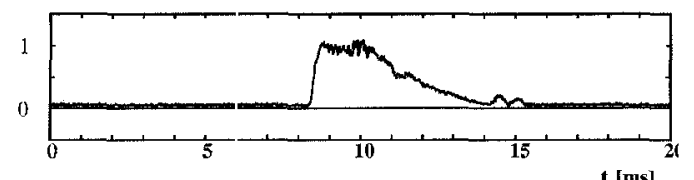

Gaplength [murn]

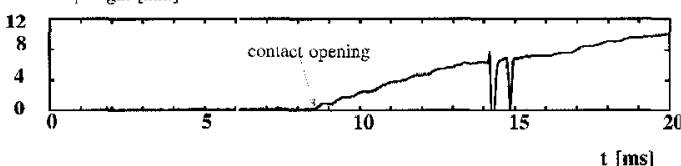

Figure 2. A typical example of a measurement with the Weil-Dobke synthetic circuit.

the cathode has reached its end position is $1 \mathrm{~m} / \mathrm{s}$. Because the contact opening speed could not be adjusted, it was not possible to set independently the arcing time and contact gap at current zero.

\subsection{EXPERIMENTAL RESULTS}

In order to obtain information about the relationship between reignition occurrence and actual re-ignition voltage $U_{r}$ on the one hand and maximum arc current $\widehat{i}_{a} \leqslant \hat{i}_{\text {gen }}$, dissipated arc energy $\int i_{a} u_{a} d t$ and contact gap length $d$ on the other hand, a large series of experiments was executed with the three different materials. During these experiments $d i / d t$ and $d U_{\mathrm{TRV}} / d t$ were kept constant at the aforementioned values. Around current zero detailed measurements of $U_{\mathrm{TRV}}$ and $i_{a}$ were made at high time resolution as shown in Figure $3[6,7]$.

In Figure 3(b) we see from $t=2.5 \mu$ s the injection current declining with a rate of $10.1 \mathrm{~A} / \mu \mathrm{s}$ and passing current zero at $t \approx 5 \mu \mathrm{s}$. The post arc current has a maximum of $\sim 1 \mathrm{~A}$ at $t=5.5 \mu$ s. Meanwhile the TRV appears (Figure $3(\mathrm{a})$ ) with a rate of $d U_{\mathrm{TRV}} / d t=1.6 \mathrm{kV} / \mu \mathrm{s}$. At $t=14.5 \mu \mathrm{s}$ re-ignition takes place at a TRV value of $-13 \mathrm{kV}$. From this high value it is clear that a dielectric re-ignition occurs. Only in a few cases, especially with $\mathrm{AgWC}$-contacts, thermal re-ignitions $\left(U_{r} \leqslant\right.$
TRV $\quad[\mathrm{kV}]$

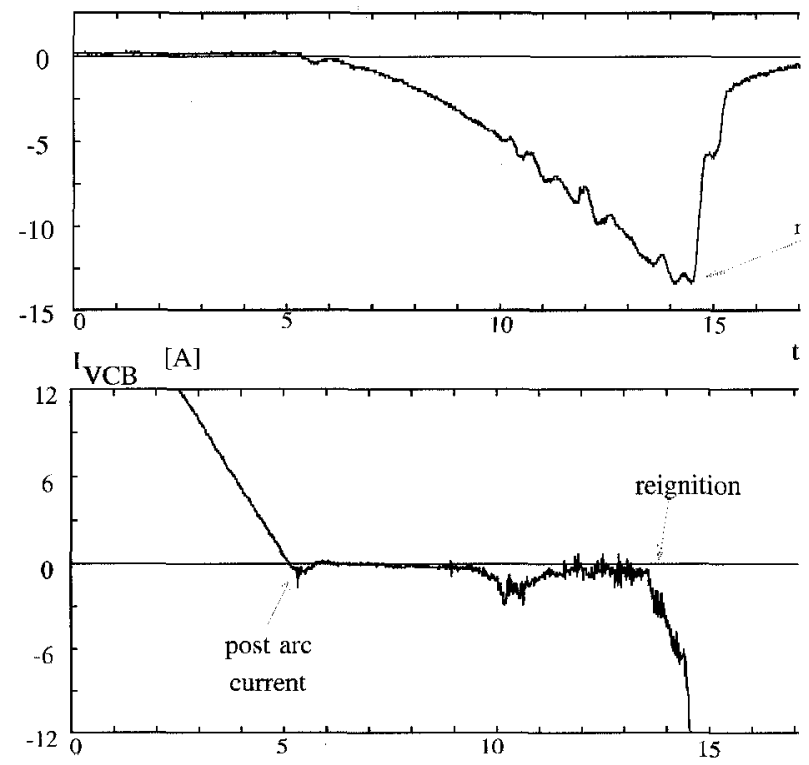

Figure 3. A typical example of fast measurements around current zero: TRV across VCB-I (a); current through the tested VCB-I (b).

$1 \mathrm{kV}$ ) were observed. On both current and voltage curves instabilities can be seen which will be discussed in Section 2 . They were observed in many experiments but do not always lead to a re-ignition.

For copper contacts some calculations and experiments were made in order to determine whether arc constriction and anode spot formation will take place at high current interruption or not $[1,2,8,9]$. The calculations are based on the method described by Rich [10] and Jolly [11] where the power density balance at the anode surface is considered. The energy input from the arc into the anode and the energy loss from the anode are determined, so the anode temperature can be found from the heat conduction theory. Essential is at what time after contact separation the anode surface temperature exceeds the copper melting temperature $T_{m C u}=1092^{\circ} \mathrm{C}$. The computational results are compared with the arc voltage and the light intensity measurements from the arc region, made by means of an optic fiber and photo-diode. The measurements are shown in Figure 4 for different values of the main current and $\sim 12 \mathrm{~ms}$ of arcing time, which covers most of the main current half period of $16 \mathrm{~ms}$. With increasing main current, a strong increase in light intensity is measured whereas the arc voltage shows a slight increase and occurrence of unstable behavior. Although the calculations predict that for case A with $\widehat{i}=4.1 \mathrm{kA}$, the anode temperature will exceed the copper melting temperature for a short period of time, the measurements (Figure 4(a)) show no effect on the arc voltage peaks or the increase in light intensity. Therefore, in this case current contraction or anode footpoint formation is not expected to happen. For case $\mathrm{B}$ with $\hat{i}=6.7 \mathrm{kA}$, the calculations predict the anode temperature to exceed the copper melting temperature at $t=4.3 \mathrm{~ms}$ where the measurements show an increase of arc voltage instabilities at $4.5 \mathrm{~ms}$. For case $C, \hat{i}=10.4 \mathrm{kA}$, the prediction of the anode temperature to exceed $T_{m C u}$ is at $3.7 \mathrm{~ms}$ where both the arc voltage and light intensity measurements show an increase at $3.8 \mathrm{~ms}$. These results, together with the strong increase in light intensity from case $B(6.7 \mathrm{kA})$ to case $C(10.4 \mathrm{kA})$ 
and the sudden jump in light intensity at $3.8 \mathrm{~ms}$ for case $\mathrm{C}$ lead to the conclusion that current constriction takes place, and that in case $C$ anode spot formation is very likely.
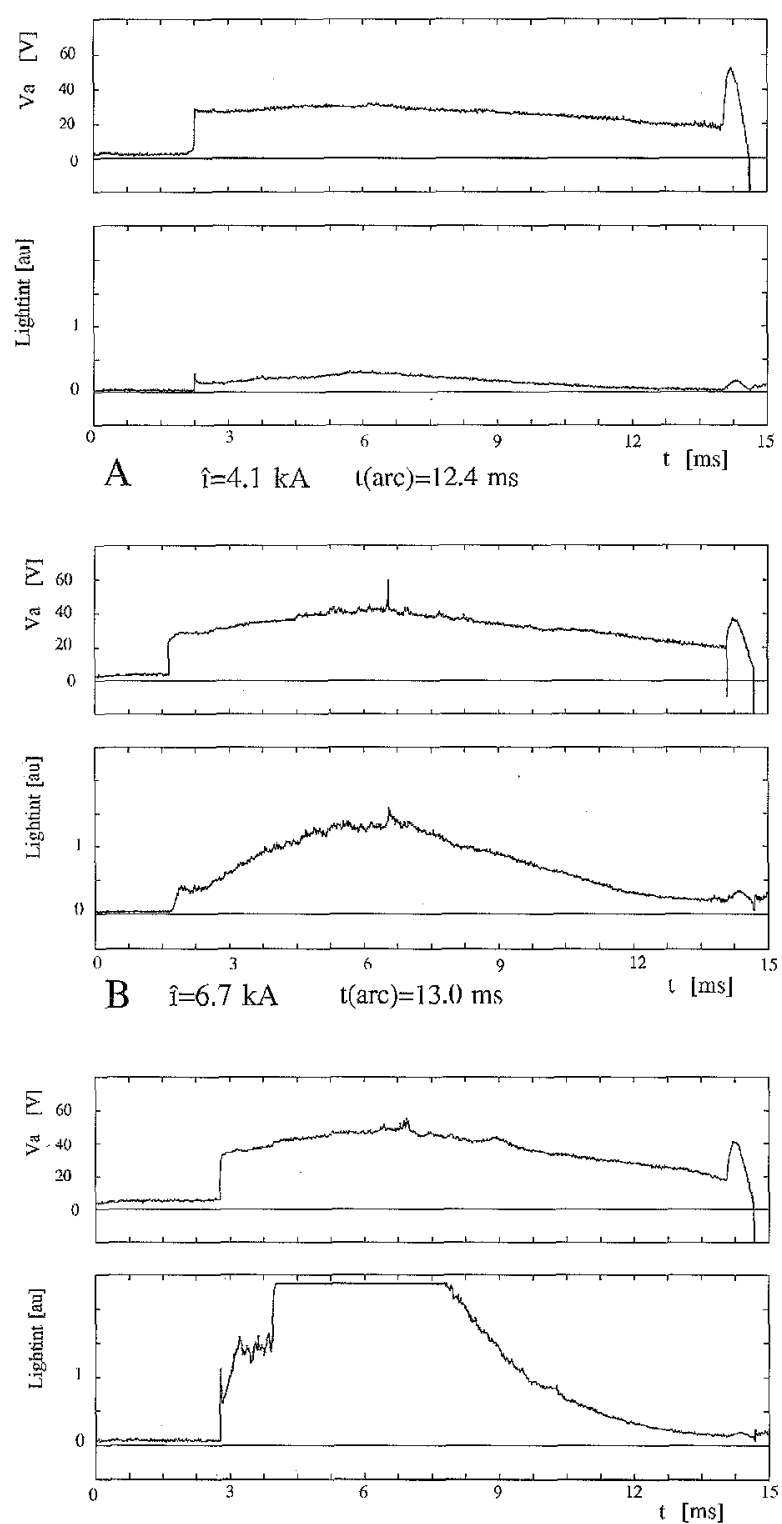

C $\quad \mathrm{i}=10.4 \mathrm{kA} \quad \mathrm{t}(\operatorname{arc})=11.9 \mathrm{~ms}$

Figure 4. Measurements of arcing voltages (upper traces) and light intensities (lower traces) for three peak currents, on copper contacts. Arcing time is kept at $\sim 12 \mathrm{~ms}$. At $10.4 \mathrm{kA}$ arc constriction is evident. (a) $\widehat{i}=4.1 \mathrm{kA},(\mathrm{b}) \hat{i}=6.7 \mathrm{kA}_{r}(\mathrm{c}) \hat{i}=10.4 \mathrm{kA}$.

Furthermore, the contact erosion rate has been determined by measuring the electrode masses before and after the interruption measurements. The average erosion rate is calculated by dividing the total electrode mass loss by the total arcing charge that was transferred in the particular measurements series. The results are compiled in Table 1.

From the Table it is clear that AgWC has the lowest erosion rate and $\mathrm{Cu}$ the highest, whereas the $\mathrm{Cu}$-anode has lost much material and the
Table 1. Erosion rates of anode "a" and cathode " $\mathrm{c}$ " for contact materials $\mathrm{Cu}, \mathrm{CuCr} 50 / 50$ and $\mathrm{AgWC}$.

\begin{tabular}{|cc|c|c|c|c|}
\hline \hline \multicolumn{2}{|c|}{ contacts } & $\begin{array}{c}\text { init mass } \\
\mathrm{g}\end{array}$ & $\begin{array}{c}\text { final mass } \\
\mathrm{g}\end{array}$ & $\begin{array}{c}\text { total charge } \\
\mathrm{C}\end{array}$ & $\begin{array}{c}\text { erosion rate } \\
\mu \mathrm{g} / \mathrm{C}\end{array}$ \\
\hline $\mathrm{Cu}$ & $\mathrm{a}$ & 205.2502 & 204.1365 & 1310 & 850 \\
& $\mathrm{c}$ & 202.8224 & 202.5963 & 1310 & 173 \\
\hline $\mathrm{Cu} / \mathrm{Cr} 50 / 50 \mathrm{a}$ & 204.2810 & 204.2739 & 2000 & 3.6 \\
& $\mathrm{c}$ & 202.5862 & 202.2660 & 2000 & 160 \\
\hline \multirow{2}{*}{$\mathrm{AgWC}$} & $\mathrm{a}$ & 202.9404 & 202.8865 & 2130 & 25 \\
& $\mathrm{c}$ & 200.5396 & 200.5247 & 2130 & 7.0 \\
\hline
\end{tabular}

$\mathrm{CuCr}$-anode only a small amount. This is also an indication for the occurrence of anode spots. A visual inspection confirmed the existence of intense arc spots on the $\mathrm{Cu}$ anode whereas the $\mathrm{CuCr}$ and $\mathrm{AgWC}$ anodes showed less evidence of severe anode melting.

\section{DISCUSSION}

\subsection{INTERRUPTION PERFORMANCE}

Under the conditions, established in the experimental setup, many interruptions led to re-ignition for all three contact materials. The interrupted main current ranges from 2.5 to $32 \mathrm{kA}$. Figure 5 shows the compiled data of re-ignition voltage $U_{r}$ and maximum main current for different regions of gap length and the contact materials $\mathrm{Cu}, \mathrm{CuCr} 50 / 50$ and $\mathrm{AgWC}$, respectively.

Cu
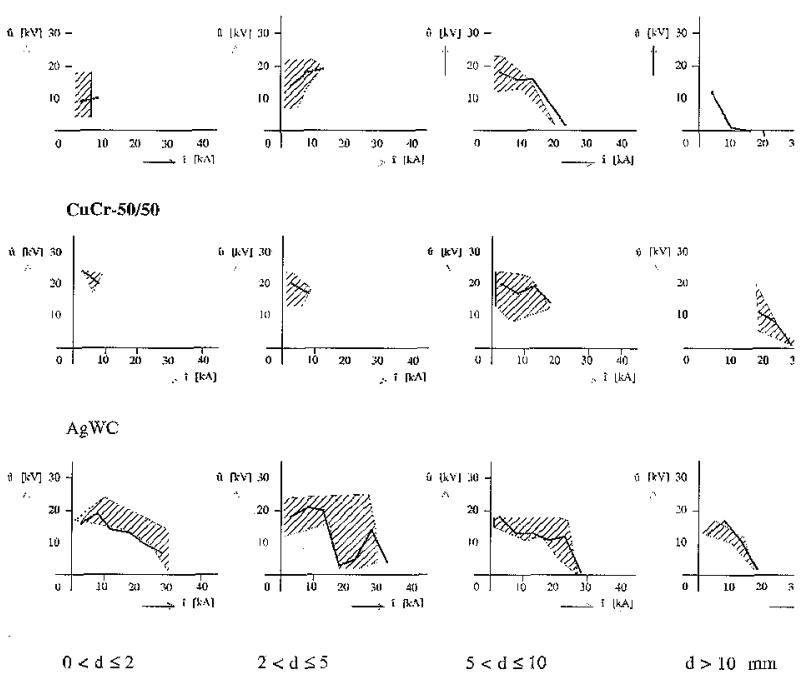

Figure 5. Envelope drawing of measured re-ignition voltages as a function of main current peak for each gap length group. The solid lines connect the mean re-ignition voltages in the particular current ranges.

The original datapoints $\left.\widehat{(i,}, \widehat{u}\left(=U_{r}\right)\right)$ are compiled in groups in the hatched areas for four different gap length regions. From this we notice that for gap lengths $d \leqslant 5 \mathrm{~mm} \mathrm{Cu}$ and $\mathrm{CuCr}$ contacts merely have dielectric restrikes, indicated by the high value of the restrike voltage, $\widehat{u}>4 \mathrm{kV}$. Within these regions of gap length the AgWC contacts show at high peak main currents, $\widehat{i}>18 \mathrm{kA}$, already occasionally thermal re-ignition, $\widehat{u} \leqslant 1 \mathrm{kV}$. In the gap lenth region $5<d \leqslant 10 \mathrm{~mm}$ the 
$\mathrm{CuCr}$ contacts show their superior behavior: they do not exhibit thermal re-ignition whereas both $\mathrm{Cu}$ and $\mathrm{AgWC}$ contacts do. Finally in the region of fully opened contact gap, $d>10 \mathrm{~mm}$, where all arc currents pass through the main current maximum, the $\mathrm{Cu}$ contacts show thermal re-ignitions for $\widehat{i}>10 \mathrm{kA}, \mathrm{AgWC}$ contacts for $\widehat{i}>15 \mathrm{kA}$ and $\mathrm{Cu}-$ $\mathrm{Cr}$ contacts prove their superiority having thermal re-ignition only for $\widehat{i}>20 \mathrm{kA}$. The thermal type re-ignitions for gap lenghts $d>5 \mathrm{~mm}$ and $\hat{i}>10 \mathrm{kA}$ are also an indication of the existence of anode spots.

In the region $d>10 \mathrm{~mm}$ two features act together: the high peak value of the main current and the long arcing time (coinciding with the large gap length). Here the total energy dissipated in the arc $W_{a}$ will result in a high concentration of cathode material in the gap and eventually when current constriction takes place and anode spots are formed, much anode material will added to the metal vapor plasma in the contact gap. In that case ionized material will stay in the inter electrode gap for $\sim 5 \mu$ s and can cause a thermal re-ignition [9]. For all three electrode materials used this has happened several times. An indication for the high plasma density $[8]$ in these cases is given by the long pumping time necessary to bring the vacuum chamber back to working conditions, pressure $p \leqslant 10^{-5}$ Pal.
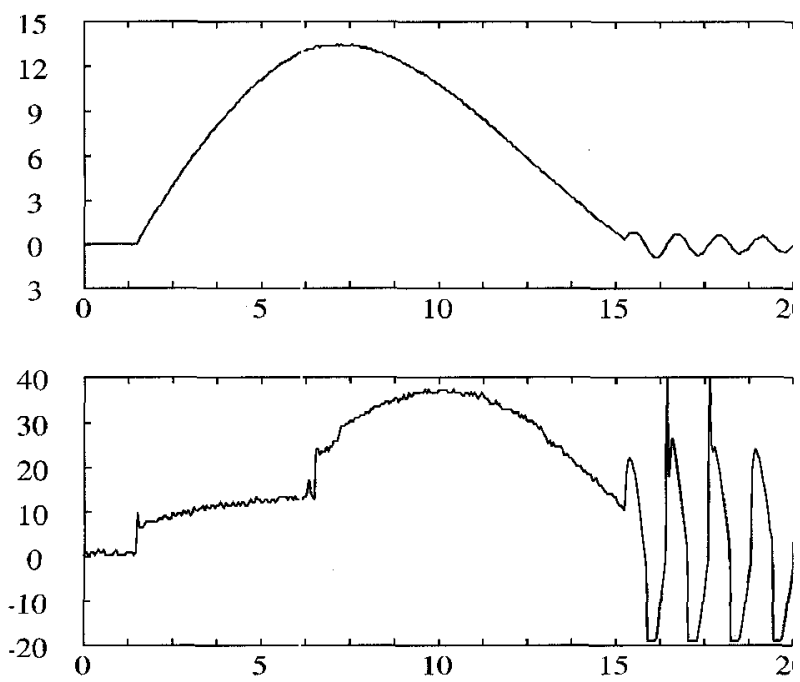

Figure 6. Specific interruption performance of $\mathrm{AgWC}$ contacts. (a) Main current and injection current with multiple re-ignitions;(b) arc voltage, suggesting thermal re-ignitions.

Figure 6 is a good exaniple of the specific performance of the AgWC electrodes. It is knowr that this contact material is especially useful for low surge circuit breakers. Figure 6(a) shows the first half cycle of the main current followed by the injection current which suffers from 9 re-ignitions, from which numbers 6 and 8 are surely thermal reignitions. This follows from the low value of the arc voltage Va that does not exceed $40 \mathrm{~V}$. The many re-ignitions observed with the AgWC contacts make it clear that they are not suited for high short circuit current interruption.

The influence of the dissipated arc energy on the re-ignition performance is best shown in Figures 7, 8, and 9 where the averaged electric field strength $E_{r}=U_{r} / d$ is exhibited as a function of the dissipated arc

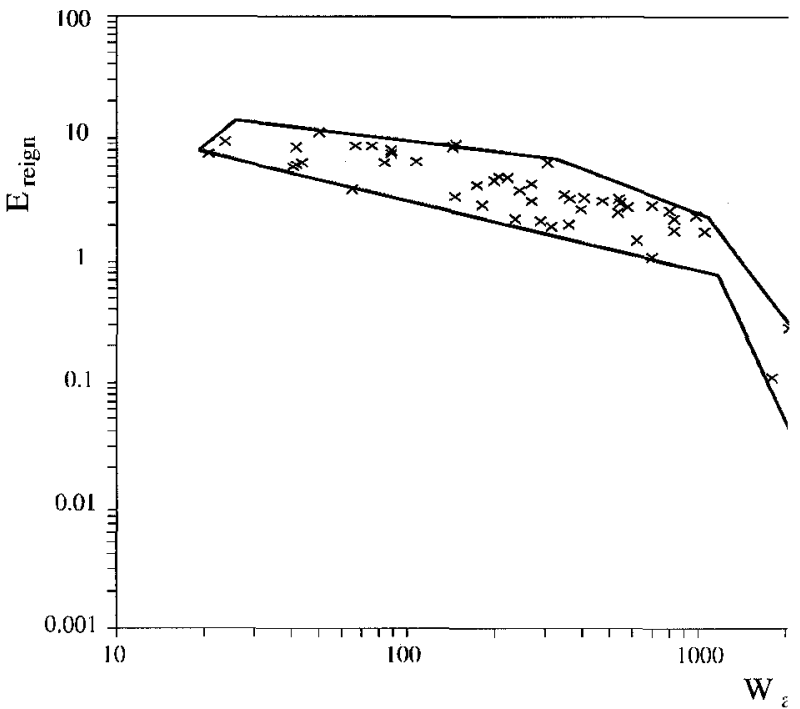

Figure 7. Re-Ignition electric field strength as a function of arc energy for $\mathrm{Cu}$ contacts.

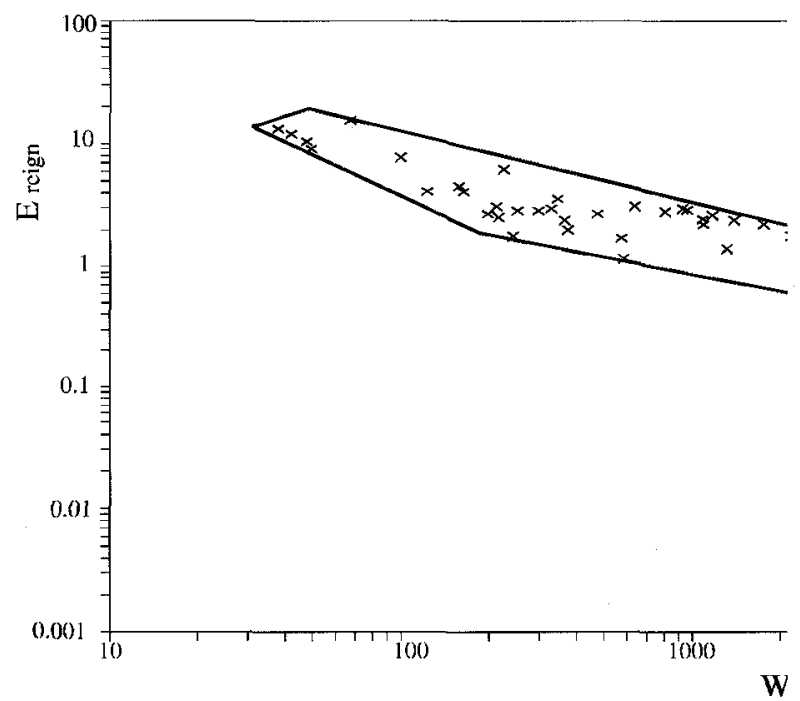

Figure 8. Re-Ignition electric field strength as a function of arc energy for $\mathrm{CuCr} 50 / 50$ contacts.

energy

$$
W_{a}=\int_{t_{a}} u_{a}(t) i_{a}(t) d t
$$

The collection of rather stochastically scattered data points in Figures 7 to 9 indicate that more features are involved than the ones mentioned in the introduction. After each interruption the surface conditions of both cathode and anode will be changed. On the cathode new craters will be formed and the anode may have new melting spots. It is known that these surface irregularities have a strong influence on the local electric field strength which in many cases plays an important role in the re-ignition process. Nevertheless the enveloping curves clearly show a tendency of declining electrical field strength $E_{r}$ with increasing arc energy $W_{a}$. For all three contact materials we see a sudden sharp drop in the re-ignition field strength above a certain critical value of $W_{a}$, see Table 2. 


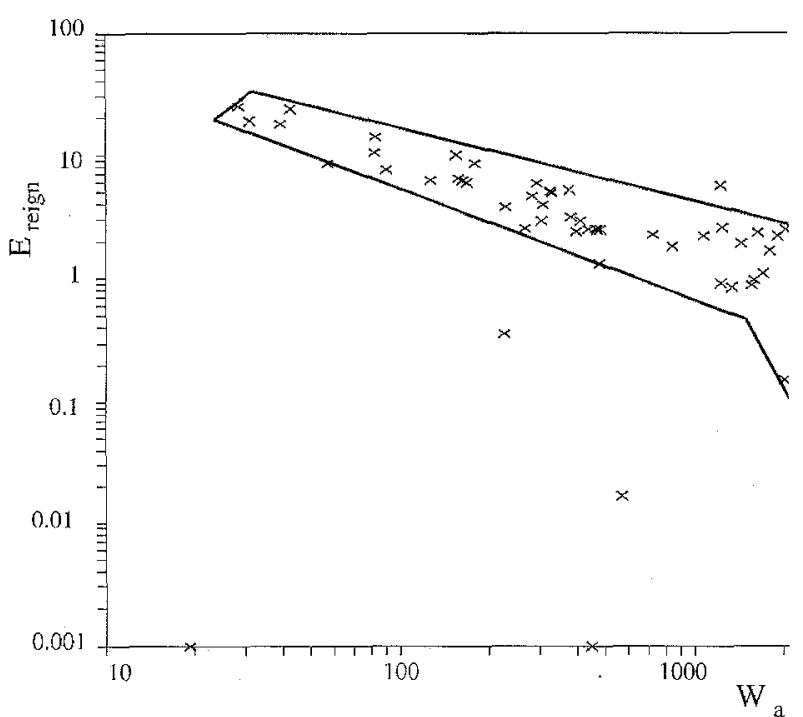

Figure 9. Re-Ignition electric field strength as a function of arc energy for AgWC contacts.

Table 2. Critical dissipated arc energy $W_{a}$ for the contact materials $\mathrm{Cu}$, $\mathrm{CuCr} 50 / 50$ and $\mathrm{AgWC}$.

\begin{tabular}{|l|c|}
\hline contacts & $\begin{array}{c}\text { crit. } W_{a} \\
\mathrm{~J}\end{array}$ \\
\hline $\mathrm{Cu}$ & 1000 \\
$\mathrm{Cu} / \mathrm{Cr} 50 / 50$ & 3000 \\
$\mathrm{AgWC}$ & 2000 \\
\hline
\end{tabular}

\subsection{SECOND POST ARC CURRENT}

In Figure 3 we have seen the appearance of a 'second' post arc current $i_{s}$ at $t \sim 10 \mu \mathrm{s}$. From the many experiments it was clear that this current peak coincides with the maximum of $d u_{\mathrm{TRV}} / d t$ and is mainly capacitive with a small resistive part. The stray capacitance of VCB-I and the plasma resistance are supposed to be the origin of this current is. The same phenomena were found with a TRV-frequency of $60 \mathrm{kHz}$ where the second post arc current appeared at $t=5 \mu \mathrm{s}$. The high frequency disturbances on $U_{\mathrm{TRV}}$ are due to the circuit $C_{\mathrm{TRV}} / L_{d} / \mathrm{VCB}-\mathrm{I}$. When the plasma resistance is low enough, re-ignition can set on as is demonstrated in Figure 3.

\section{CONCLUSIONS}

F ROM the large amount of experimental data collected during this project several conclusions about the performance of the investigated contact materials can be drawn.

First of all it is shown that with simple diagnostic means such as the measurement of arc voltage, arc current, contact movement and light intensity, the interruption performance can be fruitfully investigated.

At small gap length and peak main currents $<25 \mathrm{kA}$ all contacts materials used ( $\mathrm{Cu}, \mathrm{CuCr}, \mathrm{AgWC}$ ), showed high re-ignition voltages (> $4 \mathrm{kV}$ ) indicating dielectric re-ignition. Only AgWC contacts showed a tendency for lower re-ignition voltages at higher currents.

At large gap length, coinciding with long arcing times, a tendency is found for lower re-ignition voltages, occasionally $U_{r}<1 \mathrm{kV}$, indicating thermal re-ignition.
The re-ignition electrical field strength declines with the dissipated arc energy $W_{a}$ and at a certain critical value of the arc energy $W_{a}$ between 1000 and $3000 \mathrm{~J}$, depending on the contact material, a sudden drop of re-ignition electrical field strength by a factor of 10 was observed.

From the three materials, $\mathrm{Cu}$ showed the highest erosion rate, especially at the anode, and $\mathrm{AgWC}$ the lowest. The material loss of the $\mathrm{CuCr}$ anode was lowest indicating that it is the best choice of the three for short circuit interruption.

The experiments confirmed the capability of $\mathrm{AgWC}$ as a low surge material demonstrated by the frequent re-ignitions at low re-ignition voltages.

Evidence of severe anode spot melting was observed on $\mathrm{Cu}$ contacts only, whereas $\mathrm{CuCr}$ and $\mathrm{AgWC}$ contacts showed traces of slight anode surface melting.

The stochastic behavior of the re-ignition voltages did not show a straight correlation between contact gap length and re-ignition voltage.

A second post arc current was found, originating from the stray capaintance of the VCB and the plasma resistance, which in many cases initiated the re-ignition.

\section{ACKNOWLEDGMENT}

This project has been made possible thanks to a contract between Toshiba Corporation Fuchu Works and Eindhoven University of Technology. The authors thank Pofessor G. C. Damstra for his enthousiastic support during the experimental period.

\section{REFERENCES}

[1] G. R. Mitchell, "High Current Vacuum Arcs Part I: An Experimental Study”, Proc. IEE, Vol. 117, No. 12, pp. 2315-2226, 1970.

[2] H. C. Miller, "Vacuum Arc Anode Phenomena", IEEE Trans. Plasma Science, Vol. 11, No. 2, pp. 76-89, 1983.

[3] M. S. Agarwal and R. Holmes, "Arcing Voltage of Metal Vapor Vacuum Arc", J. Phys. D: Appl. Phys., Vol. 17, pp. 757-767, 1984.

[4] H. C. Millex, "A Review of Anode Phenomena in Vacuum Arcs", IEEE Trans. Plasma Science, Vol. 13, No. 5, pp. 242-252, 1985.

[5] M. Lindmayer and E. D. Wilkening, "Breakdown of Short Vacuum Gaps After Current Zero of High Frequency Arcs", pp. 234-241, XIV-th ISDEIV, Santa Fe, NM, Sept. 1990, edited by R. W. Stinnett.

[6] S. Yanabu, Y. Sato, M. Homma, T. Tamagawa and E. Kaneko, "Post Arc Current in Vacuum Interruptors", IEEE Trans. Power Delivery, Vol. 1, No. 4, pp. 209-214, 1986.

[7] S. Yanabu, M. Homma, E. Kaneko and T. Tamagawa, "Post Arc Current of Vacuum Interruptors", IEEE Trans. Power App. and Systems, Vol. 104, No. 1, pp. 166-172, 1985.

[8] G. Lins, "Evolution of Copper Vapor from the Cathode of a Diffuse Vacuum Arc", IEEE Trans. Plasma Science, Vol. 15, No. 5, pp. 552-556, 1987.

[9] E. Dullni, E. Schade and B. Gellert, "Dielectric Recovery of Vacuum Arc After Strong Anode Spot Activity", IEEE Trans. Plasma Science, Vol. 15, No. 5, pp. 538-544, 1987.

[10] J. A. Rich, L. E. Prescott and J. D. Cobine, "Anode Phenomena in Metal Vapor Arcs at High Currents", J. Appl. Phys., Vol. 42, No. 2, pp. 587-601, 1971.

[11] D. C. Jolly, "Anode Surface Temperature and Spot Formation Model for the Vacuum Arc", J. Appl. Phys., Vol. 53, No. 9, pp. 6121-6126, 1982.

This paper is based on a presentation given at the 17th International Symposium on Discharges and Electrical Insulation in Vacuum, July 1996, Berkeley CA, 1996.

Manuscript was received on 7 January 1997, in final form 18 October 1997. 